\title{
A NEW TECH PLATFORM AS AN INNOVATIVE TEACHING MODEL IN HIGH SCHOOLS IN THE REPUBLIC OF GEORGIA
}

\author{
Maia Noniashvili \\ Business and Technology University, Tbilisi, Georgia \\ Marine Dgebuadze \\ Business and Technology University, Tbilisi, Georgia \\ George Griffin \\ Spring Arbor University, MI, USA
}

\begin{abstract}
Modem high schools are facing challenges brought by the technological revolution. Today, leading universities have already started to use Artificial Intelligence (AI) as an instrument in teaching. This implementation will enhance education quality and emphasize an individual approach to teaching and learning. The AI environment will create a 24/7 opportunity for learning made available for student assistants using a virtual space. World leading universities also successfully apply AI in the planning of entrepreneurial activities. AI directly links science with the factors used to facilitate the growth of Georgia's economy.

The purpose of the research for this article was to show the opportunities and challenges with the use of a tech platform as an innovative teaching model in the Republic of Georgia.

Both qualitative and quantitative methods were used while conducting research. An experiment was conducted, questionnaires developed and implemented, and in-depth interviews were completed.

The research proved the readiness of the Georgian educational community to implement the innovative tech platform as a means for the quality improvement of learning. The tech platform is easily adapted for use by other countries, too.
\end{abstract}

Keywords: artificial Intelligence (Al), university, high school teaching methods, innovative tech platform, high schools, education

DOI: http://dx.doi.org/10.15549/jeecar.v7i1.386

\section{INTRODUCTION}

In this study, we examine the impact of the 2008-2009 global crisis on theft, robbery, vandalism, or arson experienced by wholesalers in Eastern European and Central Asian countries. We also investigate the influence of the crisis on these firms' spending on security. Our main objective is to see whether wholesalers were 
successful in allocating their funds (i.e. do they spend more or less money on security when a crime is more rampant?).

\section{DEFINITION OF PROBLEM}

It is perceived that the high students in The Republic of Georgia are not learning at an effective rate nor are they retaining enough knowledge to be proficient at the university level. The number of students is increasing, but the ability to effectively train them is not improving them. Implementing Artificial Intelligence Tech Platforms should reduce teaching times, increase student interest in learning, and increase retention in knowledge.

H1: Hypothesis: Implementing an Artificial Intelligence teaching program will increase student learning by $10 \%$ over students attending traditional teaching classes.

\section{INTRODUCTION}

To better prepare children for success in the twenty-first century, a growing number of high schools, universities and organizations are changing their approaches to student learning by providing personalized and active learning experiences. Many of those changes are influenced by generational and technological changes. These changes greatly influence the learning process development and also social interaction among the high school students. The development of virtual spaces for students creates an environment that delivers the information easier. The students also have the opportunity to have more active, collaborative, and technologically rich learning experiences. The research project indicated that the real challenges provided by the tech platform were more desirable and less tiring for the students.

This research project indicates that the traditional learning approach needs renovation in order to maximize learning for future students. Modem high schools are facing challenges brought by the technological revolution. Today, major universities have already started to use Artificial Intelligence (AI) as an instrument in teaching future teachers. As the newly trained teachers enter the workforce, they will be able to enhance the educational experience. The teachers can emphasize the individual learning approach and create a 24/7 student assistant and virtual space. Artificial Intelligence can be integrated into the learning experience as a hybrid model that is a blended version of face-to-face lectures and online lectures. This process will save the lecturer's time because the routine activities can be performed by the smart assistant.

The hybrid model makes the learning process more personalized and the learning resources more interesting for the student. The role of teacher becomes more of a facilitator and mentor rather the person who transmits the knowledge.

Teaching methodologies at Georgian universities are not equivalent to the methodologies and academic programs at leading foreign universities. The number of university students is increasing every year (National Statistics Office of Georgia, 2019). Also, Georgian universities are increasing their quotas for enrollments students; but the number of new undergraduates is not increasing proportionally to the new quotas (Geostat*, 2019).

The number of undergraduates is increasing in Georgia; however, the unemployment rate is getting higher every day (Geostat**, 2019). The market should be saturated by qualified professionals, but the reality is different. One of many causes of unemployment in Georgia is the gap between the learned skills of graduates that universities offer and the labor market requirements. This problem indicates that there is a problem in the educational system. Data show that many students are not taught the appropriate skills for entry into the job market at the high school level.

In Georgia, the number of qualified teachers is decreasing although the number of students seeking quality job skills is increasing. As a result, there is a significant deficiency of qualified teachers and the quality of instruction is decreasing. An unintended consequence is the increase in 
class size resulting in the use of the antiquated teaching model.

Students have expressed interest in learning through the new tech program model of teaching. It is the duty of the education system to provide an interesting and high-level effective teaching model.

One option to solve the problem is to use the new technological platform using $\mathrm{AI}$ as a hybrid model at the beginning. This model enables the individual learning approach, students' performance evaluations and other effective teaching solutions. This will also increase the teacher's role as mentor and facilitator.

The purpose of this paper is to conduct research and determine the acceptance level of Georgian high school students for the new platform implementation and its use in teaching.

\section{LITERATURE REVIEW}

The study of Artificial Intelligence platform actively started in 1950s. The main purpose of the early surveys was to determine the understanding of the platform. Consumers did not understand whether they were communicating with a robot or a human. The "Turing Test" was used to determine the level of understanding (Poole, Mackworth, 2017). In 2014, tests found that AI successfully passed this test. Since then, AI has been regularly used as a learning platform at major universities and 24-hour teaching assistant for students who become teachers in high school studies.

In higher education virtual mentors and more sophisticated platforms for learning have not been fully adapted because of the perception that even the most developed and advanced technology cannot replace the human teacher (Flickr, 2019).

Hookway (2014) introduced a balanced process concerning the usage of $\mathrm{AI}$ in higher education. He created, The Interface University Model. This model uses AI platform not as instrument in instruction but employs the third hemisphere of the human brain. This portion of the brain is responsible for creativity and cognitive learning in the teaching process - forming symbiosis, or the hybrid consciousness between humans and technology (Hookway, 2014).

The main purpose of $\mathrm{AI}$ is to improve the productivity of ongoing processes and to increase employee involvement by assisting them in fulfilling everyday responsibilities. These skills make this technology more attractive for usage by the educational system. In addition to the previous skills building, teaching becomes more internet oriented. Adaptive learning uses AI basic algorithms to personalize teaching. This process analyzes students' achievements in positive ways by reviewing their academic achievements and activities in a specific course (Dietterich, 2015).

There also is a large demand for big data analysis instruments when high schools collect data while working with students. Corporate platforms like Jenzabar cp IBM SPSS (Johnson, 2016) play the assistant role in the AI process at universities.

The Higher Education System is currently leaning towards personalized teaching. The AI process gives many options. For instance, correcting papers is an arduous task the high school teacher. The AI tech platform has the ability to find mistakes, analyze content, interpret arguments, and provide feedback to the student during the analysis of the papers. This platform can lead to effective grading for online courses, video lectures, and interrupt and give explanations to students when necessary (IBM, 2019).

Major universities have already implemented the AI tech platform in the study environment and created research and development departments to integrate $\mathrm{AI}$ in different industries.

The University of Michigan has an AI laboratory (University of Michigan, 2019). The purpose of the laboratory is to create assisting technologies for people with physical and cognitive disorders. One of the projects of the lab is the creation of automatically adaptive computer interface for blind people.

These types of AI tech platform research experiments provide effective applications in teaching for education At the University of 
Cambridge, a group of researchers was formed to work on AI tech platforms (Cambridge University, 2019). This group is investigating the application of AI tech platforms for engineering and computing theory teaching and logic.

The AI research center at Stanford University was merged with the Toyota One AI tech platform to conduct joint research in the development of smart vehicles (Stanford University, 2019).

The literature review has provided an indepth review of the Artificial Intelligence revolution. Almost every learning discipline is being investigated to determine the application of AI and its processes for each discipline. In education, the literature shows a need for innovation to improve learning and retention in high school education. In Georgia, there is a need for education innovation to improve learning and increase the number of qualified teachers to keep high-level learning. The literature review also showed that the application of $\mathrm{AI}$ increased student interest and performance. The need for AI tech platforms in education in Georgian high schools is imperative and immediate.

\section{METHODOLOGY OF THE RESEARCH}

An experiment was conducted for the project of determining the effectiveness of the application of Artificial Intelligence Tech Platforms to create dynamic and effective learning strategies. These strategies would be used by high school teachers to engage their students. Effective AI processes would create higher levels of interest in the students. A higher level of performance and retention would prepare the high school student for more intensive learning at the university level.

Stratified random sampling of the population was used. This kind of sampling is a useful combination of randomization and categorization that enabled use of both qualitative and quantitative methods. Stratification also gave us opportunity to reduce the size of the sample and make the research process more compound and precise in terms of validation. Statistical significance is expected to be achieved by this experimentation; therefore, the results and interpretation of the experiment would have validity.

Both quantitative and qualitative methods were used in the research. In terms of quantitative method experiment, observation, surveys and statistical instruments were used. In-depth interviews were held with focus groups and course mentors as qualitative method tools.

Digital platform was used for the "entrepreneurship" course. Learning materials in the Georgian language with optional questions and key phrases were embedded in the platform. The grades of students registered in previous semester on the same course were collected as baseline data to compare with the AI platform taught class. The expected goal is to observe higher grades form the AI group.

In the pilot version of the course the same amount of learning materials was used. The number weekly of lectures was reduced in half: there were five two-hour meetings (10 hours in total), 1 hour was dedicated to the evaluation.

The amount of learning materials for the experimental course was the same as the traditional course.

The aim of the contact hour reduction was to find out how the new approach and strategy (Artificial Intelligence) would help students to master the same course independently and with the same quality. If there were satisfactory results, then a 15 -week course might have a reduced number of weeks. A more diversified program curriculum could be implemented and learning enhanced.

\section{HYPOTHESIS DISCUSSION}

H1: Hypothesis: Implementing an Artificial Intelligence teaching program will increase student learning by $10 \%$ over students attending traditional teaching classes.

An analysis of the tabulated results indicates that the null hypothesis has been proved. Comparing categories, $\mathrm{A}$ to $\mathrm{D}$, between the Traditional model and the Experiment model shows an increase of $6 \%$ in learning with the Experiment group over the Traditional group. The results suggest that refinement of the delivery and the course content should be 
considered by the faculty and administration. Student achievement is the prominent goal of education and developing teaching systems that maximize this goal should be examined and implemented.

\section{RESULTS \\ Quantitative research}

The sample of 33 students was stratified in three categories: A, B, C.

Category A - students who have already successfully passed the course "entrepreneurship". They were surveyed to find out what features should be added to the platform and what elements must be taken into account to successfully implement the innovative learning model. They also formed a focus group for observation and in - depth interviews.

Category B - students who for some reasons failed to pass the course "entrepreneurship". It was important to evaluate their opinion about the pilot course, if it was more engaging, simple and easy to master compared to the traditional one.

Category C - students from other universities and disciplines who have never attended an entrepreneurship course. It was important to observe such students and learn their attitude towards the new learning method.

Basic statistical data were used for quantitative comparison of population of 400 students and the number of students participating in experiment.

Results are compared using a university 100-point assessment system, where points are distributed according to the following scheme:

(A) 91-100 Excellent

(B) 81-90 Very Good

(C) 71-80 Good

(D) 61-70 Satisfactory

(E) 51-60 Sufficient

(FX) 41-50 Unsatisfactory, a student is given an extra chance to take the final examination

(F) 0-40 Failure, a student has to pass the course anew for gaining credits.
Chart 1. Evaluation comparison.

\begin{tabular}{|c|c|c|}
\hline $\begin{array}{l}\text { Evaluation } \\
\text { category } \\
\text { (grade) }\end{array}$ & $\begin{array}{c}\text { Population (20 } \\
\text { contact hours) } \\
\text { traditional }\end{array}$ & $\begin{array}{c}\text { Experiment } \\
\text { (10 contact } \\
\text { hours) AI } \\
\text { model }\end{array}$ \\
\hline A & $16 \%$ & $12 \%$ \\
\hline B & $14 \%$ & $24 \%$ \\
\hline C & $20 \%$ & $12 \%$ \\
\hline D & $20 \%$ & $29 \%$ \\
\hline E & $22 \%$ & $3 \%$ \\
\hline F & $8 \%$ & $21 \%$ \\
\hline
\end{tabular}

As the Chart 1 shows, the number of students that earned an A (91-100) during the traditional course represented $16 \%$ of the group, but the AI experiment group only $12 \%$ scored in the highest percentile. In addition, the number of students who failed during the experiment is higher, compared to the number of the traditional lecture students. These numbers deny the assumption that the experiment course was easier.

Observing the data, one can conclude that the number of students is reduced in grade $\mathrm{E}$ - and they represent only $3 \%$. Grade $\mathrm{E}$ is sufficient for the student to get credit. This increases students' distribution in B and D categories. The result once more proves that the platform is successful the for individual approach. As noted by mentors, the evaluation scheme in case of experiment was more transparent and fairer. During the traditional course $22 \%$ of students got credit by getting low, but sufficient grades (the number of failed students is increased - 21\%), in the experiment group students failed or improved results (D category number is increased - 29\%). As for high marks, for students it was harder to get higher grades (A category was reduced) compared to traditional course; however, many of them were attending the class for second time.

A negative correlation is observed between the data, indicating the outcome of the course minimized by the twice reduced contact hours. 


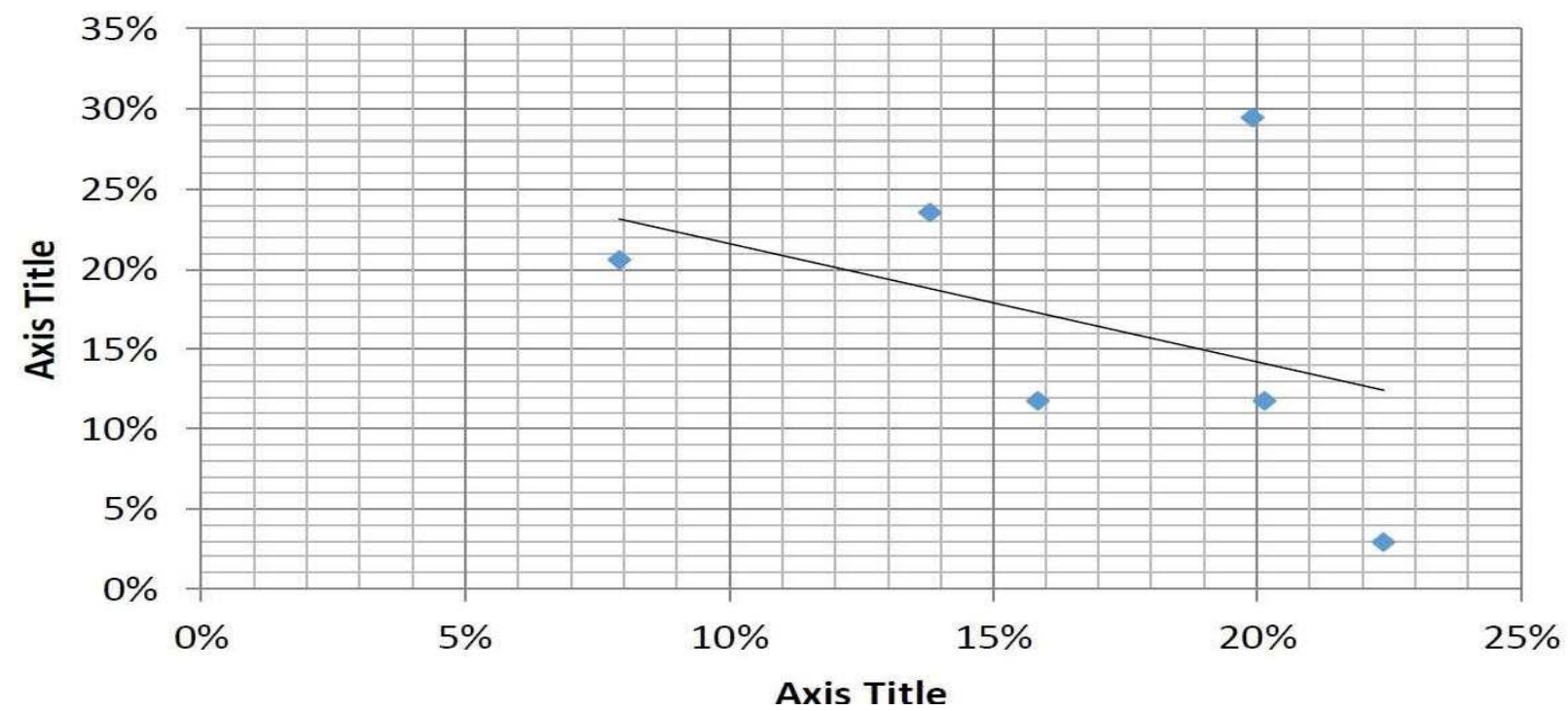

Figure 1. Data correlation

We can make comparison of other statistical indicators to validate research results.

Chart 2. Comparison of statistical data

\begin{tabular}{|l|c|c|c|c|c|}
\hline Category & $\begin{array}{c}\text { Average } \\
\text { grade }\end{array}$ & $\begin{array}{l}\text { Average } \\
\text { difficulty }\end{array}$ & $\begin{array}{l}\text { Standard } \\
\text { deviation.* }\end{array}$ & Range & Correlation \\
\hline population & 68 & 0,68 & 0,048 & 77 & \multirow{2}{*}{$-0,41$} \\
\hline experiment & 73 & 0,73 & 0,088 & 95 & \\
\hline
\end{tabular}

* The average difficulty was computed by dividing the smallest mark of this course by the highest mark of the same course.

** The standard deviation was calculated by the formula:

$$
S=\sqrt{\frac{\sum_{i=1}^{n}\left(x_{i}-\bar{x}\right)_{i}^{2}}{n-1}}
$$

When $\bar{x}$ is the sample mean, $n$ is the number of members of a sample.

*** the correlation was calculated by the formula:

When $\bar{x}$ and $\bar{y}$ are means of $x$ and $y$ variables.

$$
r=\frac{\sum\left(x_{i}-\bar{x}\right) \times\left(y_{i}-\bar{y}\right)}{\sqrt{\sum\left(x_{i}-\bar{x}\right)^{2} \times \sum\left(y_{i}-\bar{y}\right)^{2}}}
$$

As shown in chart 2, the average mark indicators, as average difficulty indicators differ by $7 \%$ in favor of the experiment, and the difference between coefficients of standard deviations dispersion is $83 \%$, that is caused by the existence of marks of those students who are passing the course for the second time. This was expected and proves the accuracy of calculations once more.

\section{Zualitative Research}

A group of participants was also formed into a focus group and there were in-depth interviews with all of them. The interview was based on open ended questions. Interviewees were free in expression of their 
views. The aim of focus group was to find out the opinion of those students who succeeded in both, traditional and innovative forms of the "entrepreneurship" course.

Thirteen out fifteen respondents participated, and the questions were as follow:

I. how would you evaluate "entrepreneurship" course in traditional form, when you passed it during your studies? (difficult, easy, interesting, boring, useful)

2. How did the amount of learning material differ in case of traditional and innovative platform model?

3. How did the content of learning material differ in case of traditional and innovative platform model?

4. Is it possible the for traditional teaching to be replaces by the platform in most of thecourses?

5. How convenient was the time saving, resource availability, individual approach and less contact hours with lecturer in case of new model?

6. Express your opinion regarding the interaction with $\mathrm{AI}$ in new model

The "entrepreneurship" course in the new format for the majority of the participants was interesting, useful, and easy. Only three of the respondents believed that the learning materials were the same as the traditional course. Others commented that in the traditional course, the materials were more theoretical, informative and greater in volume. They noted that in case of traditional course there also were articles and other additional readings that gave them general knowledge of the subject. In case of the experiment group the learning materials were less, but still very comprehensive and task oriented, also easy to understand. It made their learning process easy and engaging.

One of the participants noted that in the traditional course topics were split in lectures, and in the experiment model they were unified, but still complete. Many of them also considered that even in case of less information the new course gave them all necessary skills and information to transform existing idea into a start-up.

As for the content, all of the participants agreed that it was similar in both formats of the course. The majority of the participants believe that the new platform is effective and has potential to replace the traditional method nearly in all learning courses, because it makes lectures more engaging, easy and interesting. But, at the present moment it needs further development. One of the respondents thinks that AI will never be able to replace the human teacher.

Innovative teaching methods using the AI platform for all of the participants was convenient, simple, sophisticated, and inventive. Convenience for them was less time consumption, learning material availability, individual approach and distance learning. It gave them the chance to prepare the lesson even in case of absence on lecture. For two students it was convenient, because of the interaction with AI. AI interaction was positively evaluated by all participants.

Interviews were also held with the course mentors, who were same for the traditional and innovative courses. They were the ones who prepared materials for the platform. In case of the experiment (AI) the role of the teacher was completely different. The process was not teacher oriented. She played the role of a mentor who was mediator between students and the platform while working on tasks. This made the process more active and student oriented, also more personalized.

Observations prove that teachers used platform freely, the learning process was active and interesting. Observers did not notice any interruption of the class while working with platform.

During the interviews, both teachers said that the course in new format was more interesting, easy and entertaining. The engagement of students was high. Both teachers agree that students mastered the course effectively. The evaluation process was transparent and just. Using the platform teachers are able to justify any mark by the task submitted from the students, that is more convenient compared to traditional 
grading in case of oral presentations. One of the lecturers was satisfied with working and using the platform, while the other one thought that the course materials and resources should be richer and more detailed. The latter one thinks that this kind of simplification is not a good decision. Both mentors recommended further development of the platform by adding video lectures, visual materials, projects and etc. In their opinion this will lead to more time saving and effective teaching.

\section{CONCLUSION}

The research results prove the success of the innovative platform integration in the learning process, its ability to improve teaching quality and individual approach. It simplifies the teachers' working process making the lecture more interesting and engaging. It is recommended that the platform be implemented in the teaching of other subjects.

In case of reduced contact hours this method is proven to be effective. It is also need to further research and financial analysis application.

Although the small numbers (33) in the study are not statistically significant, they do indicate the importance of continuing the discussion of the effects of AI on the educational system. The Republic of Georgia should continue to analyze the concepts of the AI Tech Platform and discover the particular components of the system that can have a positive effect in the teaching process in Georgia.

As new teachers who are familiar with AI permeate the Georgian school system, the quality of learning will improve.

The goal of education will be achieved and job availability and performance will be increased.

\section{REFERENCES}

Chassignol, Maud, Aleksandr Khoroshavin, Alexandra Klimova, and Anna Bilyatdinova. 2018. " Artificial Intelligence Trends in Education: A Narrative Overview." In
Procedia Computer Science, 136:16-24. Elsevier B.V. Retrieved from |https://doi.org/10.1016/j.procs.2018.08.233

Clarke, Roger. 2019. " Regulato ry Alternatives for Al." Computer Law and Security Review. Retrieved from https://doi.org/10.101 6/j.clsr.2019.04.008

Dietterich Th. G., Benefits and Risks of Artificial Intelligence. , AAAI Press., 2015 Flickr., IBM Watson Paths Research Project. Retrieved from https://www.flickr.com/photos/ibm research zurich/albums/72157636361743526/with/1 01739493931

Hookway B., Interface., ISBN: 9780262525503., MIT press., April 2014 IBM. Retrieved from http://wwwOl.ibm.com/software/analytics /spss/academic/solutions/administ rators.html

Johnson C., Adaptive Learning Platforms: Creating a Path for Success., educause.edu., 2016

Kumar, Poonam, Anil Kumar, Shailendra Palvia, and Sanjay Verma. 2019. " Online Business Educati'on Research: Systematic Analysis and a Conceptual Model." International Journal of Management Education 17 (1): 26-35. Retrieved from https://doi.org/10.1016/j.ijme.2018.11.002.

National Statistics Office of Georgia., Geostat., Retrieved from https://www.geostat.ge/en/modules /categories/61/higher education

National Statistics Office of Georgia., Geostat., Retrieved from https://www.geostat.ge/en/modules /categories/38/employment-andunemployment

Ocana-Fernandez, Yolvi, Luis Alex Valen zuelaFe rnandez, and Luzmila Lourdes GarroAburto. 2019. "Inteligencia Artificial y Sus Implicaciones En La Educaci6n Superior." Prop6sitos y Repre sentaciones 7 (2). Retrieved from https://doi.org/10.20511/pyr2019.v7n2.274

Poole D., Mackworth A., Artificial Intelligence Foundations of Computational Agents., Cambridge University Press., 2017 
Stanford University. Retrieved from go.nmc.org/sailtoy

University of Michigan. Retrieved from go.nmc.org/umail

University of Cambridge. Retrieved from go.nmc.org/claiuc

\section{ABOUT THE AUTHORS}

Ayse Nilgun Balas, email: abalas@vsu.edu

Ms. Maia Noniashvili is PhD student at Business and Technology University, Tbilisi, Georgia. She started her academic career at Ilia State University. She possesses IO-year experience in teaching. She teaches course of Operations Management to undergraduate and postgraduate students. At different period she has conducted courses in Business Basics, Economic Principles and Management. Her research focus is Management, Industrial Revolution 4.0, Education Management, and Business. She has been supervisor of tens of Masters' papers and author of many articles.

Dr. Marine Dgebuadze is a Full Professor at Business and Technology University, Republic of Georgia. She teaches Academic Writing and Research Methods to bachelor, masters and PhD students of Business and Technology University. She is Individual Member of World Education Research Association. Her research is focused on education and teaching methods problems in Georgia. Her publications on these subjects include journal articles, case studies and research papers published in Europe and Georgia. She attends many international scientific conferences.

Dr. George Griffin is a Professor Emeritus in the School of Graduate and Professional Studies at Spring Arbor University since 1995. George received a Fulbright Scholar Award in 2010 and taught business courses at Ilia State University, Tbilisi, Georgia for one semester. He has presented papers at eight conferences and published multiple manuscripts. Dr. Griffin joined the academic team at JEECAR to influence studies of economics in Eastern Europe and Central Asia universities. He received another Fulbright Award and will return to Georgia in April 2014 to teach at Ilia State University for six weeks. In 2016, Dr Griffin received his third Fulbright Scholar Award and he worked with SASTRA University, Tamil Nadu, India to develop an educational system based on the American Community College system for SATRA University. 